\title{
Lusioersily
}

\section{Extruded high-temperature thermoplastic tufting yarns for enhanced mechanical properties of composites}

Mc Garrigle, C., Fernández, D., Middendorf, P., Dooher, T., Kelly, J., Mcllhagger, AT., Harkin-Jones, E., \& Archer, E. (2019). Extruded high-temperature thermoplastic tufting yarns for enhanced mechanical properties of composites. Journal of Reinforced Plastics and Composites. https://doi.org/10.1177/0731684419886368

Link to publication record in Ulster University Research Portal

Published in:

Journal of Reinforced Plastics and Composites

Publication Status:

Published online: 10/11/2019

DOI:

$10.1177 / 0731684419886368$

\section{Document Version}

Author Accepted version

\section{General rights}

Copyright for the publications made accessible via Ulster University's Research Portal is retained by the author(s) and / or other copyright owners and it is a condition of accessing these publications that users recognise and abide by the legal requirements associated with these rights.

\section{Take down policy}

The Research Portal is Ulster University's institutional repository that provides access to Ulster's research outputs. Every effort has been made to ensure that content in the Research Portal does not infringe any person's rights, or applicable UK laws. If you discover content in the Research Portal that you believe breaches copyright or violates any law, please contact pure-support@ulster.ac.uk. 
Journal of

Reinforced Plastics and Composites

\section{Extruded High Temperature Thermoplastic Tufting Yarns for Enhanced Mechanical Properties of Composites}

\begin{tabular}{|c|c|}
\hline Journal: & Journal of Reinforced Plastics and Composites \\
\hline Manuscript ID & JRP-19-0201.R2 \\
\hline Manuscript Type: & Original Article \\
\hline $\begin{array}{r}\text { Date Submitted by the } \\
\text { Author: }\end{array}$ & 05-Sep-2019 \\
\hline Complete List of Authors: & $\begin{array}{l}\text { McGarrigle, Cormac; Ulster University, School of Computing, } \\
\text { Engineering and Intelligent Systems } \\
\text { Fernández, Daniel; Universitat Stuttgart Institut fur Flugzeugbau, } \\
\text { Departments of lightweight design and fiber composite technology } \\
\text { Middendorf, Peter; Universitat Stuttgart, Institut für Flugzeugbau } \\
\text { Dooher, Thomas; Ulster University, School of Computing, Engineering } \\
\text { and Built Environment } \\
\text { Kelly, John; Ulster University , School of Engineering } \\
\text { McIlhagger, Alistair; University of Ulster, Engineering Composites } \\
\text { Research Centre } \\
\text { Harkin-Jones, Eileen; University of Ulster, Engineering Research Institute } \\
\text { Archer, Edward; University of Ulster, Engineering Composites Research } \\
\text { Centre }\end{array}$ \\
\hline Keyword: & Composites, Tufting, Extrusion, Thermoplastic \\
\hline Abstract: & $\begin{array}{l}\text { Through-thickness stitching, in the form of tufting, has been shown to be } \\
\text { a potentially successful method of improving resistance to delamination. } \\
\text { Tufting is a single sided stitching technique that involves the insertion of } \\
\text { a yarn through a fabric, in the z-direction. However, further research } \\
\text { into the development of a tailored tufting yarn could yield a greater } \\
\text { improvement in the mechanical properties of the overall composite. } \\
\text { Unlike other published works which rely on commercially available } \\
\text { materials, for this study four thermoplastic yarns were produced from: } \\
\text { polyetheretherketone, polysulfone, polyethersulfone and } \\
\text { polyphenylsulfone. Their ability to be tufted into a composite was } \\
\text { examined along with their influence on the overall mechanical properties } \\
\text { of the composite. }\end{array}$ \\
\hline
\end{tabular}

\section{SCHOLARONE Manuscripts}


Original article

Corresponding Author:

\title{
Cormac McGarrigle,
}

Ulster University Magee, Co Derry, Northern Ireland. BT48 7JL

Email: c.mcgarrigle1@ulster.ac.uk

\section{EXTRUDED HIGH TEMPERATURE THERMOPLASTIC TUFTING YARNS FOR ENHANCED MECHANICAL PROPERTIES OF COMPOSITES}

\author{
Cormac McGarrigle ${ }^{*}$, Daniel Fernández², Peter Middendorf², \\ Thomas Dooher ${ }^{1}$, John Kelly ${ }^{1}$, Alistair McIlhagger ${ }^{1}$, Eileen Harkin- \\ Jones $^{1}$, Edward Archer ${ }^{1}$ \\ ${ }^{1}$ Engineering Research Institute, Ulster University, Northern Ireland \\ ${ }^{2}$ Institut für Flugzeugbau, Universität Stuttgart, Germany
}

\begin{abstract}
Through-thickness stitching, in the form of tufting, has been shown to be a potentially successful method of improving resistance to delamination. Tufting is a single sided stitching technique that involves the insertion of a yarn through a fabric, in the z-direction. However, further research into the development of a tailored tufting yarn could yield a greater improvement in the mechanical properties of the overall composite.

Unlike other published works which rely on commercially available materials, for this study four thermoplastic yarns were produced from: polyetheretherketone, polysulfone, polyethersulfone and polyphenylsulfone. Their ability to be tufted into a composite was examined along with their influence on the overall mechanical properties of the composite.
\end{abstract}

\section{Key Words}

Composites, tufting, tensile strength, extrusion

\section{INTRODUCTION}

Fibre-reinforced composite (FRC) laminates support significant improvements in strength-to-weight ratio when compared to materials traditionally used in aerospace and automotive industries. ${ }^{1}$ These FRC laminates boast anisotropic mechanical properties due to their consisting of varied orientations of laminates. This allows the user to tailor the composite properties as directionally required. ${ }^{2}$

Carbon fibre composites typically consist of thin carbon fibre layers to give the desired thickness and properties. When subjected to interlaminar stress these multi-layered, or laminate, composites are highly 
susceptible to delamination; a loss of local stiffness in a composite material which is subjected to either static loading or cyclic loading. ${ }^{3,4}$ Through-thickness reinforcement is a method of reducing delamination in a laminate composite by increasing its interlaminar properties. This is performed by means of a third directional reinforcement of through-thickness fibres in the z-direction, usually before the resin impregnation step. ${ }^{5}$ These reinforcement fibres can be generated by a number of means, such as weaving, z-pinning, stitching, tufting or braiding. ${ }^{4}$ The introduction of a stitched through-thickness reinforcement allows for easier handling of the preform, reducing the likelihood of damage or shifting of the preform layers. ${ }^{6}$

Tufting is a single sided stitching technique that involves the insertion of a yarn through a fabric, in the zdirection. Tufting arrests the displacement caused by crack opening displacement in mode I loading and crack sliding in mode II. The tufting thread functions as a pin, retaining the adjacent laminate regions following the transit of a delamination crack front through said region, providing reinforcement at the region of the stitch insertion and between the stitches. ${ }^{7}$ These loops are retained in position as the yarn is a friction fit in the insertion hole through the material. The process begins with a pressure foot on the tufting head compressing the preform. The needle vertically penetrates the preform thus inserting a continuous yarn to the required depth. This newly inserted yarn is then returned through the same trajectory in which it was inserted resulting in the formation of a loop of yarn on the back face of the reinforced material, as seen in Figure 1. This allows the yarn to remain in place while under little or no tension. ${ }^{8}$ The tuft loops are kept as short as possible to reduce the risk of overlapping which can happen during compaction in the infusion stage as this would result in the formation of a weak resin-rich layer on the outer edge of the composite..$^{9,10,11}$

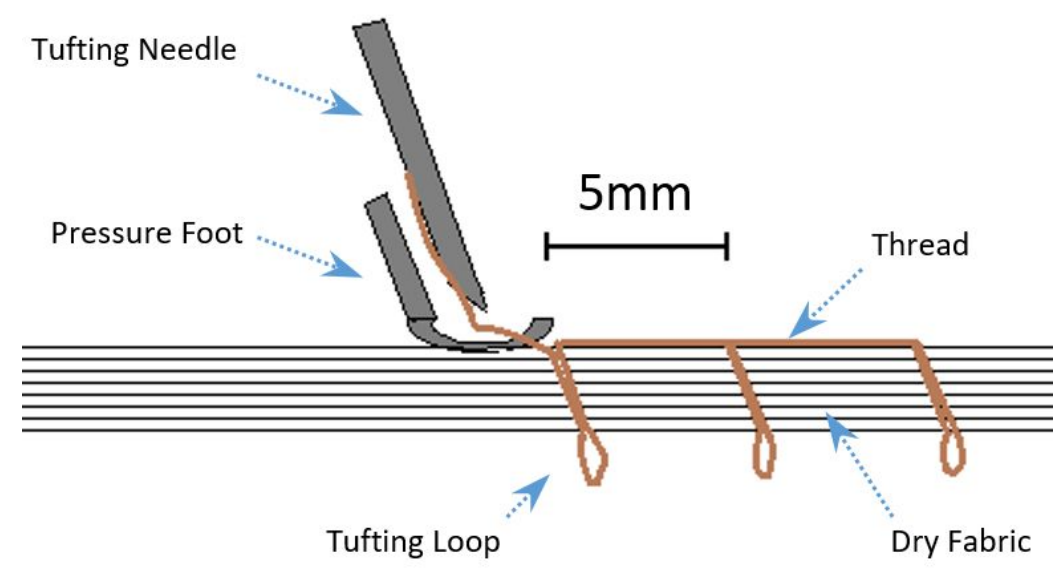

Figure 1: Tufting Process 
One method for the production of through-thickness stitched dry textile preforms is the insertion of continuous carbon fibre, which is very stiff and with good mechanical properties, ultimate tensile strengths of around $3000 \mathrm{MPa}$, into the preform. The mechanical manipulation of the brittle carbon fibre yarn during the tufting process can result in thread damage to the inserted carbon fibre resulting in a negative influence on the mechanical crack bridging properties of the composite. ${ }^{12,13}$ Preliminary testing has indicated that polyetheretherketone (PEEK), polysulfone (PSU), polyethersulfone (PES) and Polyphenylsulfone (PPSU) are potential candidates for such a tufting yarn due to their excellent mechanical, physical and thermal properties and their reduced tendency for damage during the tufting process. ${ }^{14}$

\section{Materials and Methods}

\section{Extrusion}

Prior to the extrusion process all polymers were dried individually in an oven at $150^{\circ} \mathrm{C}$ for a period of 2 hours in order to remove any moisture within the material. ${ }^{15} \mathrm{~A}$ Thermos Scientific HAAKE Rheomex PTW 16 OS twinscrew extruder combined with a Thermoscientific Type L-002-0061 pelletizer, modified to be used as a haul-off unit, were used for all of the extrusions. A screw temperature of $360^{\circ} \mathrm{C}$ was used to extrude polysulfone and polyethersulfone. Polyphenylsulfone and polyetheretherketone were extruded at $385^{\circ} \mathrm{C}$. All of the yarns were drawn at a haul-off rate of 1200rpm. These were produced as monofilament yarns, with the following

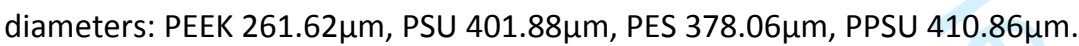

\section{Tufting Yarn Tensile Strength}

An Instron 3344 tensile testing machine, equipped with a 500N load cell and Series 2710-200 Screw Action Grips, was used to test the tensile strength of the tufting yarns prior to insertion into the carbon fibre layups. ASTM D3822/D3822M-14 "Standard Test Method for Tensile Properties of Single Textile Fibres" was followed for the testing of the polymer yarns in a straight direction. ${ }^{16}$ In order to examine how the yarns would perform during the tufting process they were tested in both looped and knot configurations using ASTM D3217-07 "Breaking Tenacity of Manufactured Textile Fibres in Loop or Knot Configurations". ${ }^{17}$ A gauge length of 1inch, $25.4 \mathrm{~mm}$, was selected for use in all configurations. Resin and card tabs were manufactured at ends of the fibres to aid gripping and in an attempt to prevent potential fibre damage from the grips causing the fibres to break at the grips and thus invalidating the tests. 


\section{Tufting}

A KSL 522 tufting head was mounted on a KUKA 125/3 robot operated with a KCP2 controller for all of the tufting. A modified KL 125 Groz-Beckert needle was fitted to the tufting head. The needles were modified by removing their exterior ridge, which is designed to spread the material being tufted, and by smoothing out the eyelet with Mitchell's abrasive chord. A linear speed of $15 \mathrm{~mm} / \mathrm{s}$ was used and the distance between the stitches along the seam, the stitching pitch (Lp), was set as $5 \mathrm{~mm}$, as shown in Figure 1 . Each of the monofilament thermoplastic yarns were tufted into a $400 \mathrm{~mm} \times 200 \mathrm{~mm}$ layup comprised of 8-layers of 0/90, 285g/m2 5 harness satin carbon fibre from Toho Tenax HS 6k.

\section{Composite Manufacture}

The tufted preforms were infused with Cytec (Solvay) Cycom 890 resin system and cured in a pressurised autoclave at $180^{\circ} \mathrm{C}$ for 2 hours. ${ }^{18}$

The fibre volume fraction, $\mathrm{Vf}$, is the volume of the fibre component of a composite expressed as a percentage of the entire composite volume. This was used to calculate the composite component thickness as follows:

$$
V_{f}=\frac{n A_{w}}{\rho_{f} t}
$$

\section{Equation 1: Fibre Volume Fraction Calculation ${ }^{19}$}

Where,

$\begin{array}{llll}A_{w} & \text { Areal Weight of fabric } & \rho_{f} & \text { Fibre Density } \\ t & \text { Component Thickness } & n & \text { Number of layers }{ }^{20}\end{array}$

$6 \mathrm{~K} 285 \mathrm{gsm} 5$ harness satin was used for all of the laminates. The density of the fibres was taken from the manufacturer's material data sheet to be $17600 \mathrm{~kg} / \mathrm{m}^{3} .^{21}$

It is expected that the introduction of the tufting yarns will misalign the in-plane fibres on either side of the tuft in order to accommodate the tufting yarn forming an "eye" shaped resin-rich region around the tuft. This is hypothesised to increase with the compression of the laminate fibres and to give a local increase in fibre volume fraction, $\mathrm{Vf}$, of the tufted composites when compared with the baseline sample. ${ }^{22}$ 
Using the previously calculated Vf values, the composite rule of mixtures was applied to predict a stiffness for each of the composite panels, disregarding their tufted reinforcement, as follows:

$$
E_{L}=E_{1}^{F} V_{f}+E_{m}\left(1-V_{f}\right)
$$

Equation 2: Longitudinal Modulus from Rule of Mixtures

$V_{f} \quad$ Fibre Volume Fraction of Fibres Aligned with the Stress

$E_{1}^{F} \quad$ Modulus of Fibre $\quad E_{m} \quad$ Modulus of Resin

The fibre volume fraction was taken from the result of Equation 1 and the modulus of the fibre was the same as used in Equation 1. The modulus of the resin was taken from the manufacture's material data sheet which showed it to be $1.2 \mathrm{GPa} .{ }^{23}$

\section{Composite Tensile Strength}

The methodology described in ASTM D3039/D 3039M - 08 "Tensile Properties of Polymer Matrix Composite Materials" was followed for all of the composite tensile testing. ${ }^{24}$ Glass-fibre reinforced polymer tabs were bonded to either end of the tensile specimens to prevent damage to the test specimens during gripping. One side of the specimens was prepared for digital image correlation (DIC) by means of the application of a speckle pattern. 2-axis strain gauges from Tokyo Sokki Kenkyujo Co. Ltd (TML) were bonded to each sample on the alternate side. These were connected to the National Instruments DAQ in order to measure strain.

The samples were subsequently loaded in the warp direction into an Instron 5500R tensile tester with the gauge length set to $150 \mathrm{~mm}$. A constant cross-head speed of $2 \mathrm{~mm} / \mathrm{min}$ was used for all of the tensile testing and a $50 \%$ drop in load set as the test termination condition.

\section{Composite Open-Hole Tensile Strength}

The open-hole tension tests were performed in accordance with ASTM D5766/D5766M - 11 "Open-Hole Tensile Strength of Polymer Matrix Composite Laminates". ${ }^{25}$ A central pilot hole was drilled though each sample prior to them being reamed with a $1 / 4$ inch EDP 4204 one shot drill reamer from Mohawk specifically designed to eliminate the possible delamination upon both entry and exit of the reamer. As with the unnotched tensile samples these were also prepared and tested with glass fibre tabs, a 2-axis strain gauge and a speckle pattern. 


\section{Digital Image Correlation}

A StrainMaster Portable from LaVision was used. A 2-dimensional set up consisting of a 5 M-lite 5 megapixel camera, 2 LED light sources and a StrainMaster Controller was set up on the provided tripod, as below:

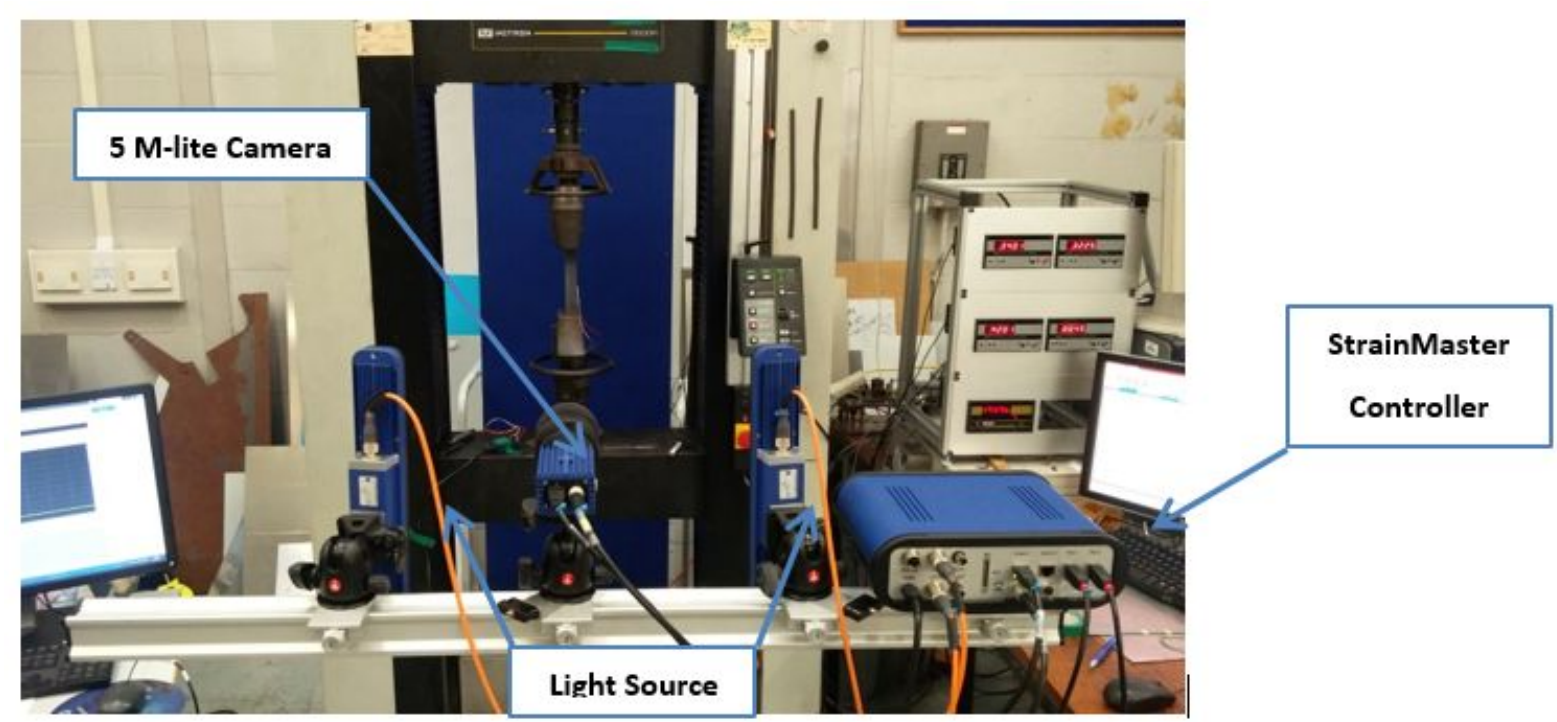

\section{Figure 2: Digital Image Correlation Set-Up}

The camera was equipped with a Tokina 100mm F2.8 D AT-x Pro macro lens to maximise light into the camera for an improved image.

\section{X-Ray Microtomography}

3-dimensional models of $64 * 13 \mathrm{~mm}$ samples of each of the tufted composites were produced using a Brunker SkyScan 1275 automated micro-CT. These X-ray microtomographs, or micro-CT images, were used to determine whether any structural damage had been caused by tufting or if any defects exist within the samples.

No filters were applied during the recording of the images. The specimen was placed on a rotating brass specimen holder and held in place by means of dental wax. The scan parameters were set in the Skyscan 1275 software in order to provide a contrast between the differing regions of density within the samples. The images were then processed and the area of interest reconstructed in a 3-dimensional rendering of the object. Following this reconstruction CT-Vox software was used to analyse the 3-D model.

\section{Short-Beam Shear Strength}


In this test the material, in a beam shape, is loaded in a normal three-point bend schematic. The test piece is constructed to certain predefined dimensions to ensure the introduction of interlaminar shear failure. ASTM D2344/D2344M-16 “Standard Test Method for Short-Beam Strength of Polymer Matrix Composite Materials and Their Laminates" describes the test set up used. This is the specimen length being equal to 6 times the thickness and the width being double the thickness of the sample. ${ }^{26}$ The dimensions of the tufted short-beam shear samples are presented in Table 2 below:

\section{Table 1: Short-Beam Shear Test Configuration}

\begin{tabular}{|c|c|c|c|}
\hline $\begin{array}{c}\text { Stitching } \\
\text { Material }\end{array}$ & $\begin{array}{c}\text { Sample } \\
\text { Thickness }(\mathbf{m m})\end{array}$ & $\begin{array}{c}\text { Sample } \\
\text { Length }(\mathbf{m m})\end{array}$ & $\begin{array}{c}\text { Sample Width } \\
(\mathbf{m m})\end{array}$ \\
\hline \hline Non-Tufted & 3.15 & 18.92 & 6.31 \\
PEEK & 2.75 & 16.5 & 5.5 \\
PSU & 2.75 & 16.5 & 5.5 \\
PES & 3.25 & 19.5 & 6.5 \\
PPSU & 3.1 & 18.6 & 6.2 \\
\hline
\end{tabular}

\section{Results}

The results for the yarn tests are shown in Figure 3. Since the PEEK and PPSU had the most consistent diameters, their tensile properties were expected to exhibit less variation than the other yarns. Unlike other brittle yarns in previous research studies by Dell'Anno et al., the thermoplastic yarns tested here did not suffer a property decrease when knotted. When knotted, the PSU's UTS actually increased by $3.8 \% .{ }^{11} \mathrm{~A}$ similar trend occurred when looped, as can be seen in Figure 3. It is proposed that this enhanced yarn robustness will enable successful tufting with minimal yarn damage when compared to conventional tufting yarns. 


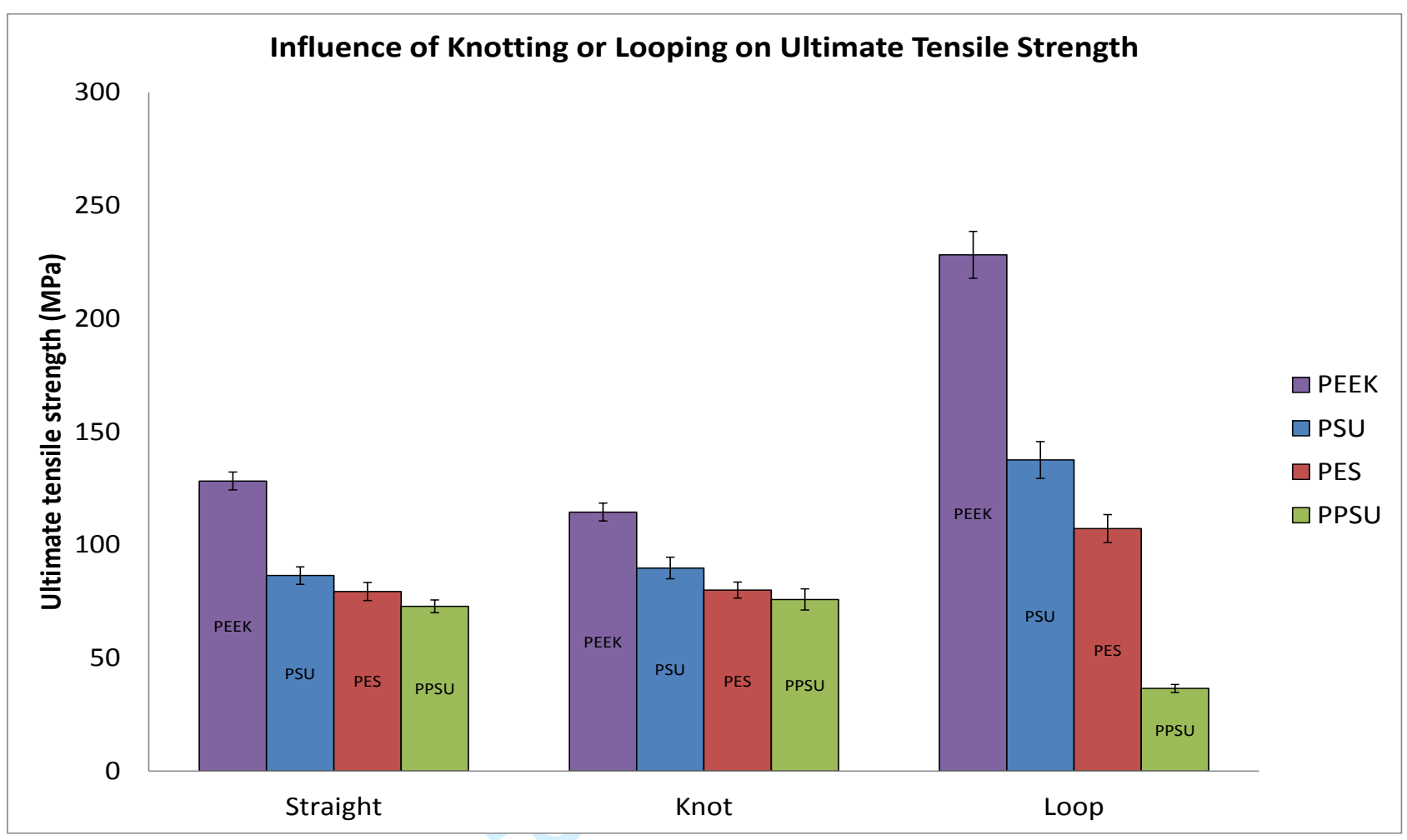

Figure 3: Influence of Knotting or Looping on Ultimate Tensile Strength

Dransfield et al. show a reduction in the UTS of their conventional stitching yarns once looped, in contrast to the thermoplastic yarns used here whose UTS actually increased when tested in the loop configuration. ${ }^{27}$ The reason for this has not been confirmed but it is thought to have been partially influenced by the lower Young's modulus of the thermoplastic yarns compared with commercially used yarns, as can be seen in previous work from the author. ${ }^{14}$

Figure 4 below shows a micrograph of one of the PEEK Tufted composites prior to tensile testing. It can be seen that through the composite there are tufting reinforcements. At the outer edge of the composite the compressed tufting loops are visible. This has caused a small resin-rich region. The full lengths of the loops are not visible in this cross section as the tufting yarns are inserted at around $30^{\circ}$ into the composite. This is evident from Figure 10 which shows a $\mu \mathrm{CT}$ scan through a tufted composite. 
Figure 4: PEEK Tufted Tensile Sample Prior to Testing

Figure 5 illustrates the ultimate tensile strength of the tufted composites as per ASTM D3039/D 3039M testing procedure. The non-tufted composite's UTS was 44.62MPa less than the PEEK tufted composite, giving a $7.57 \%$ increase in ultimate tensile strength. The consistent diameter and good mechanical properties of the PEEK yarns could account for this. The PEEK tufted composites exhibited a $54.87 \%$ increase in UTS over the PPSU tufted composite. However, the PPSU tufted composite's UTS was $180.12 \mathrm{MPa}$, or $30.54 \%$, less than the nontufted carbon composite. It is postulated that a number of factors could influence this result such as: the diameter variation of the PPSU yarn causing stress concentrators within the narrow sections and resulting in premature failure, the PPSU yarn having the lowest tensile properties and least extension out of all of the polymer yarns used and the difficulty stitching with the PPSU yarn resulting in multiple breaks within the yarn.

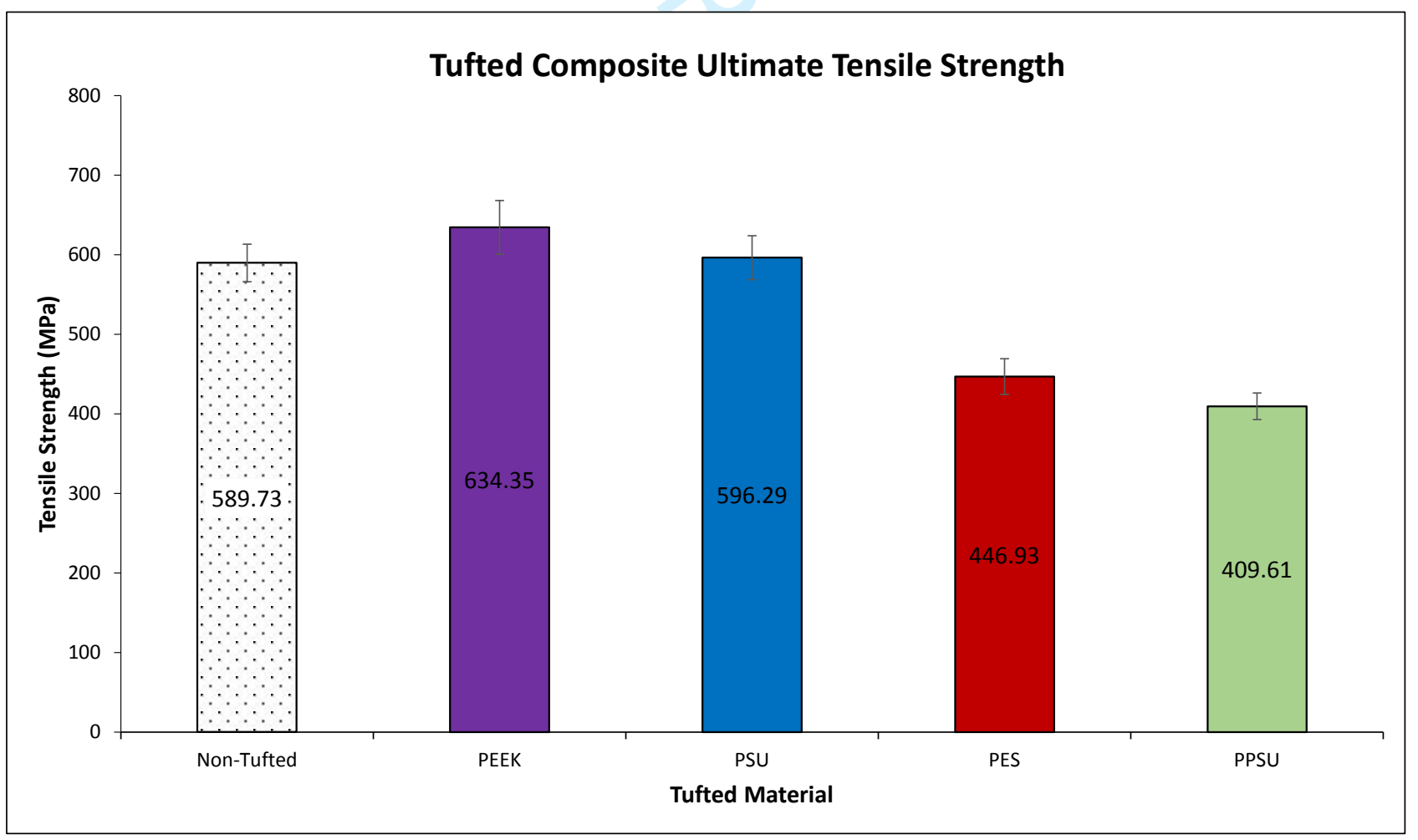

Figure 5: Tufted Composite Ultimate Tensile Strength 
Aside from variations within the diameter of the polymer yarns, and their ability to bend without fracture or kinking, there seemed to be no definitive parameters noted that resulted in a tuftable yarn.

The average thickness of the composites was measured and subsequently the $V_{f}$ of the tufted composites was calculated using Equation 1. As the tufting yarns protrude through the composite to form the tufting loop they influence the overall thickness of the composite. However, as can be seen from Figure 4 the yarns tend to misalign the laminate's fibres lowering their position into the composite and as such reducing their protrusion significantly. ${ }^{11}$ As a result of this their influence on the thickness of the panels was not thought to be significant. As such the calculated volume fraction results are as follows:

Table 2: Volume Fraction of Tufted Samples

\begin{tabular}{|c|c|c|}
\hline $\begin{array}{c}\text { Stitching } \\
\text { Material }\end{array}$ & $\begin{array}{c}\text { Sample } \\
\text { Thickness (mm) }\end{array}$ & $\begin{array}{c}\text { Volume } \\
\text { Fraction (\%) }\end{array}$ \\
\hline Non-Tufted & 3.15 & 51.4 \\
PEEK & 2.75 & 58.9 \\
PSU & 2.75 & 58.9 \\
PES & 3.25 & 49.8 \\
PPSU & 3.1 & 52.2 \\
\hline
\end{tabular}

With the exception of the PES yarn, the introduction of the tufting yarns resulted in the expected increase in Vf which, according to Dell'Anno et al., is as a result of the extra compression of the laminate during infusion. It is expected that some of the variation in the mechanical results may be related to the varying fibre volume content. $^{11}$

Figure 6 shows the typical stress-strain curve for a non-tufted composite tensile specimen. The curve shows both the values obtained from the DIC and the strain gauge. It can be seen that both curves lie in relatively the same location. The strain map from the DIC at various strain levels is shown along the curve.

At 0.001 strain, the strain map has some small regions of 0 to negative strains as the composite is beginning to take up the load. At 0.004 strain it can be seen that all of the composite is under loading. The final DIC strain map, at around 0.007 strain shows stress concentrations becoming more prevalent in certain regions within the composite and reducing in other areas of the composite. In this study, these regions tended to be at the outer edge of the composite along the centre of the gauge length, ultimately failing across the length of the composite. 
Figure 6: Tufted Composite Young's Modulus from DIC

Using the calculated $V_{f}$ values, the composite rule of mixtures was applied to predict the stiffness of each of the composite panels, disregarding their tufted reinforcement. Their predicted stiffness is as follows: Nontufted 61.2MPa, PEEK 70.0MPa, PSU 70.0MPa, PES 59.3MPa and PPSU 62.4 MPa.

The Young's Modulus values obtained from the strain gauge system during the composite tensile testing is graphically displayed below in Figure 7. The predicted values of the Young's modulus closely align to the measured values below, with the exception of the PPSU tufted composite. The Young's modulus for PPSU could have been lower than predicted due to a combination of the issues with tufting. This resulted in multiple breaks along the yarn within the composite resulting in inconsistency in the reinforcement and potentially poorly reinforced regions. In contrast, PEEK tufted composite provided a $24.6 \%$ increase in Young's Modulus over the non-tufted composite, whereas the PPSU tufting resulted in a decrease of $7.8 \%$ in Young's Modulus. 


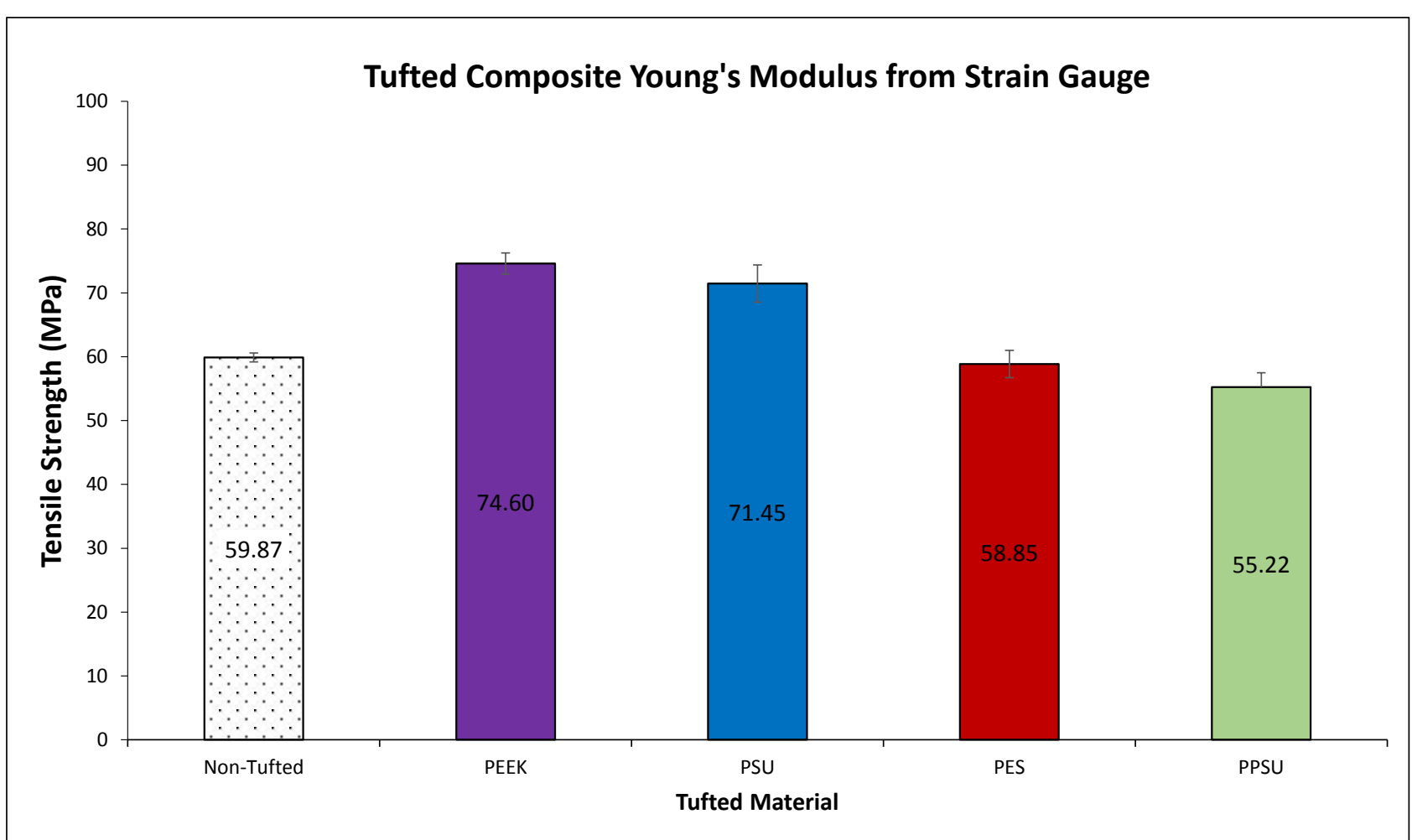

Figure 7: Tufted Composite Young's Modulus from Strain Gauge

This could, potentially, be partially caused by the fibre misalignment as a result of the insertion of the tufting yarns. Even a few degrees of fibre misalignment from the tensile loading direction will cause a significant reduction in the strength of the composite. Fibre breakage as a result of the insertion of the tufting yarn is also possible. ${ }^{28}$ However, Herszberg et al. have suggested that in light of the proportion of broken fibres as a result of stitching being quite low, $<0.5 \%$, proposing instead that fibre spreading is the main culprit in the deterioration in both strength and stiffness of the stitched composite. ${ }^{29}$ As with the values from the strain gauge, the DIC also showed the PEEK tufted composite produced a $24.6 \%$ increase in Young's Modulus compared to that of the non-tufted sample. Unlike the strain gauges the DIC showed just a $1.04 \%$ decrease in the Young's modulus of a composite once tufted with PPSU.

Fibre distortion or misalignment, resulting in small resin-rich pockets, could be seen in varying amounts across both the CT scans and the micrographs. The stray carbon ends seen in the micrograph of the PEEK tufted composite in Figure 8 suggest that the fibres were broken as a result of the tufting process. 


\section{Figure 8: PEEK Tufted Composite Micrograph}

Depending on the material used the influence of the tufting yarns on the mechanical properties of the composite varies substantially.

The ultimate tensile strength of the tufted composites measured during open-hole tension testing are shown below in Figure 9 . The non-tufted sample suffered a $43.2 \%$ knockdown in UTS from the tensile samples to the open-hole tensile samples. The PEEK samples suffered a $40.3 \%$ knockdown compared to the tensile specimens. Dissimilar to the tension samples, all of the tufted open-hole tension samples showed an increase in UTS over the non-tufted samples.

The PEEK tufting yarn provided a $13 \%$ increase in UTS when tufted into the open-hole tension composite samples. Even the PPSU tufting yarn yielded a $4.3 \%$ increase in UTS under this configuration. The PES yarn provided only a $6.5 \%$ increase in UTS. The suspected cause of these low increases is the porosity observed within the composite from the $\mu \mathrm{CT}$ scans, as is evident in Figure 12. 


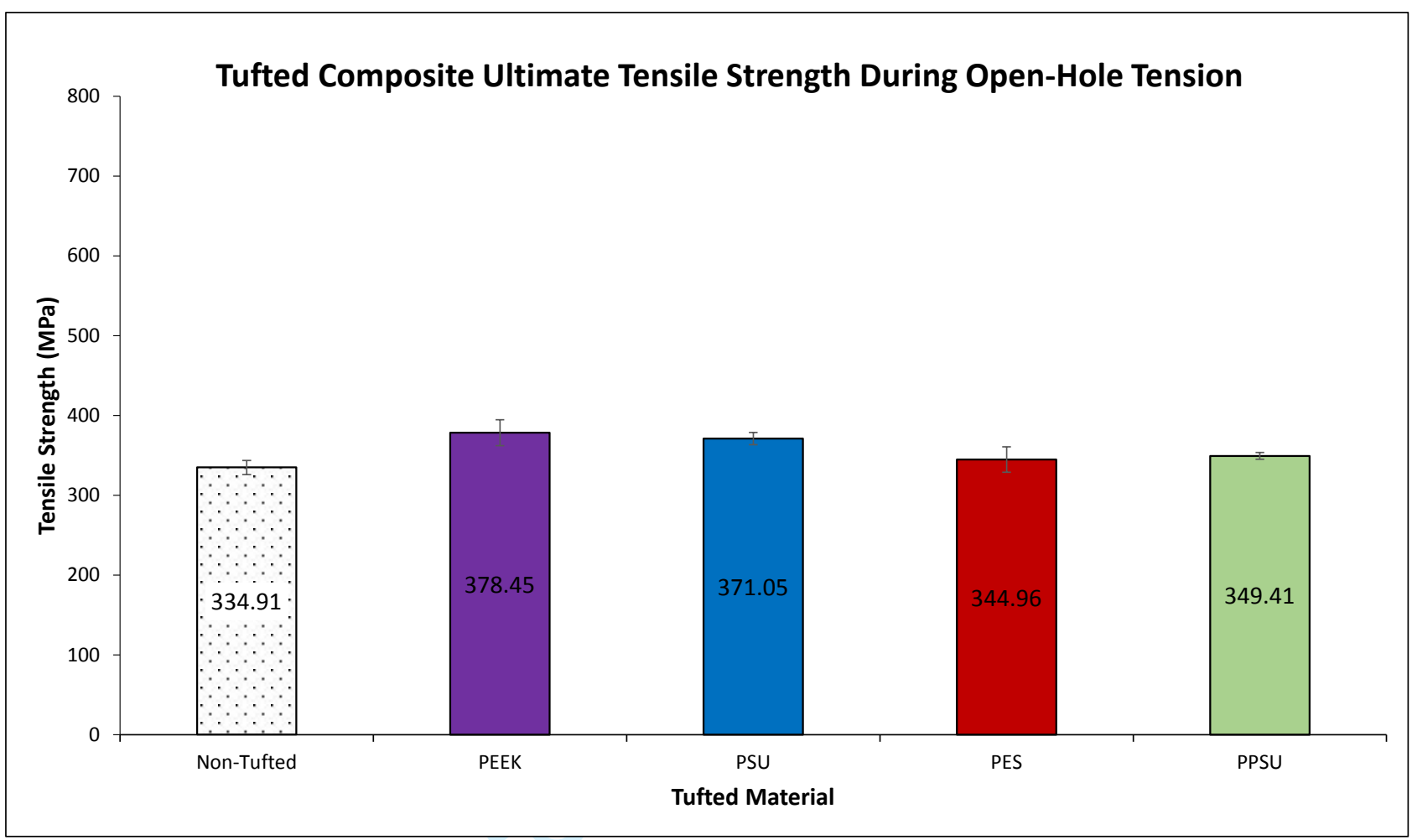

Figure 9: Tufted Composite Ultimate Tensile Strength During Open-Hole Tension

Little difference was observed between the strain maps for the tufted composites and those of the non-tufted composites. In general within the literature, and evident from work by Koissin et al. showing strain fields of tufted composites, the site of the tuft insertion into the composite is often recorded as an area of greater strain. ${ }^{30}$ It is thought that the less brittle nature and lower diameter of the tufting yarns in this project made them difficult to observe on the DIC. This, coupled with the reduced degree of fibre misalignment when using a lower diameter tufting yarn, potentially attributed to the lack of variation between the tufted strain maps and the non-tufted strain maps.

Along with the previously mentioned fibre damage within the composite the $\mu \mathrm{CT}$ scans also revealed voids along the surface of the PSU, PPSU and PES tufted composites. These voids existed in different locations along the tufted loops right through-the thickness of the composite as can be seen in Figure 10 below. This could be attribute to the reinforcement of the composite with PES, PPSU and PSU having a lower UTS than the PEEK tufted composite. There are numerous potential reasons why this could have occurred, such as the surface roughness of those polymers acting as cavities. These cavities could cause bubble nucleation by providing 
potential sites for the formation of bubbles within the liquid resin which could subsequently cure into regions of porosity. ${ }^{31,32}$

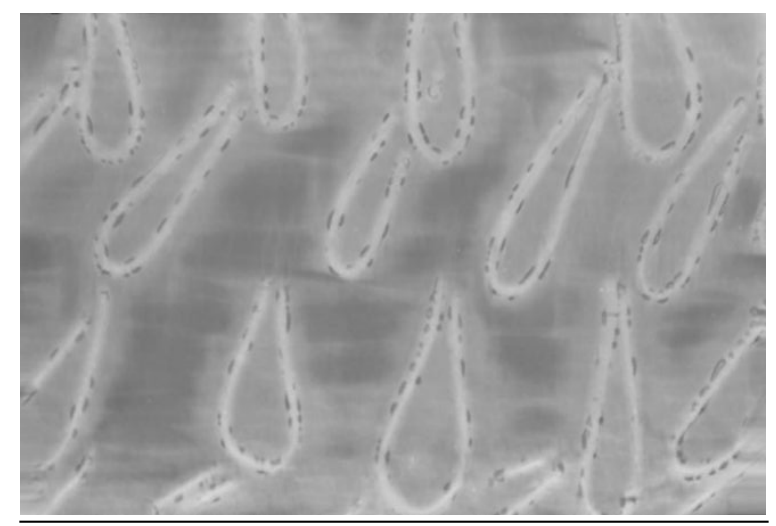

Figure 10: PES Tufted Composite CT Image

In Figure 11 a $\mu \mathrm{CT}$ scanned image of a PES tufted composite is shown colourised in an attempt to display the orientation of the tufting yarns through the composite. It can be seen that the tufting yarns are inserted at an angle, around $30^{\circ}$, similar to work performed by Scott et al. who suggested this angle would increase the volume of thread within the laminate and potentially increase its influence on the mechanical properties of the composite by affecting of the disturbance path the fibre causes within the preform. ${ }^{10}$

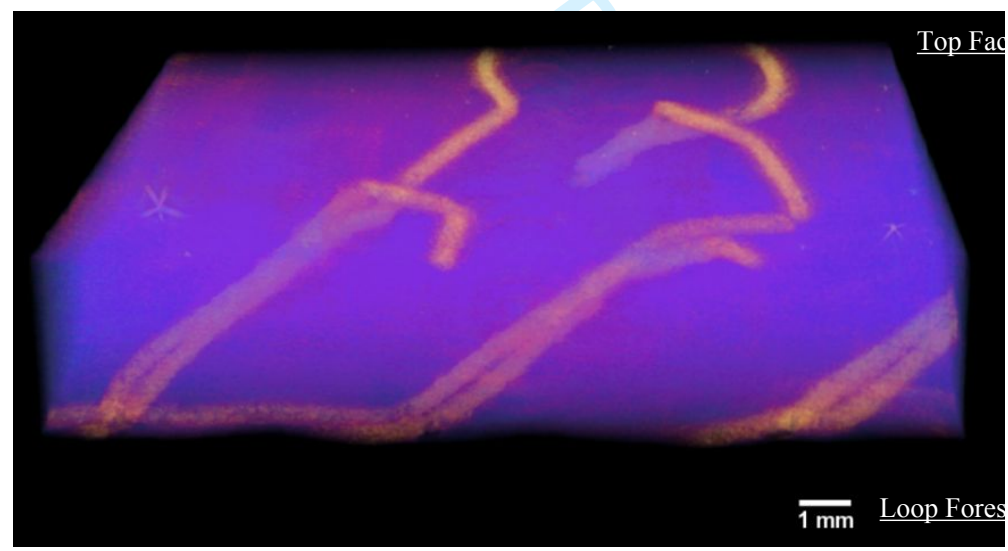

Figure 11: PES Tufted Composite Colourised $\mu \mathrm{CT}$ Image

Each of the infused tufted composites were tested under the short-beam shear configuration as per ASTM D2344/D2344M-16. The delamination crack caused during the test is shown in Figure 12 below: 


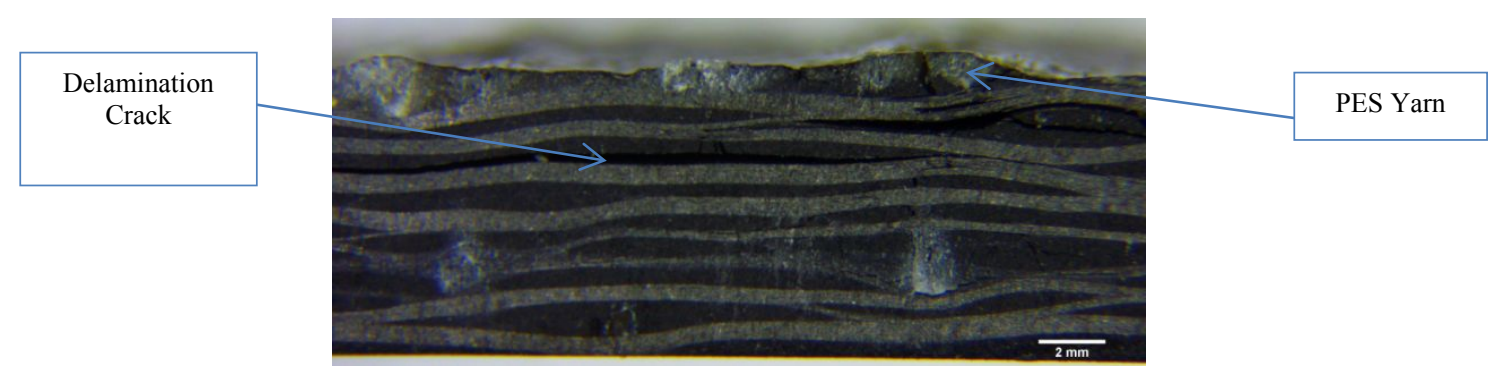

Figure 12: Failed PES Tufted Composite

Despite the PEEK thermoplastic yarn having an ultimate tensile strength 41.78MPa greater than the PSU yarn, the PSU yarn exhibited a larger short-beam shear strength. No firm correlation can be drawn from the thermoplastic yarn's ultimate tensile strength and short-beam shear values. However, the two thermoplastic yarns with the least deviation in their diameter, PEEK and PPSU, also had the least variation in their shortbeam shear strengths, as can be seen from the error bars in Figure 13. This would suggest that diameter consistency of the thermoplastic yarns could attribute to more consistent mechanical properties under certain test configurations.

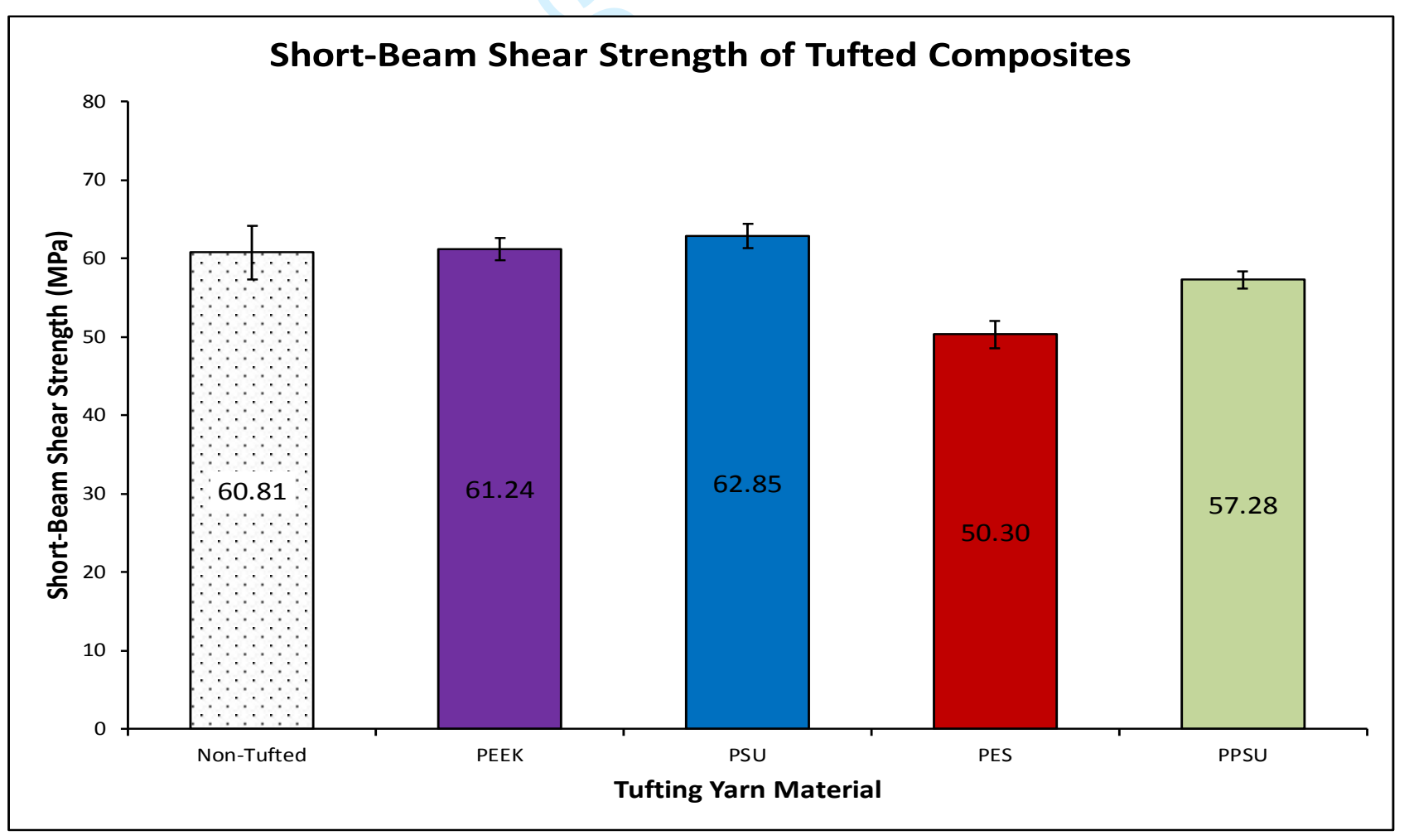

Figure 13: Short-Beam Shear Strength of Tufted Composites

The benefits of tufting on short-beam shear strength with these polymers appears to be nearly non-existent when compared with the non-tufted, other than reducing the variation in the short-beam shear strength, 
compared with the non-tufted. PSU yarn gave a short-beam shear strength increase of $3.4 \%$ whereas introduction of the PES yarn resulted in a $17.3 \%$ decrease in short-beam shear strength. This could be caused by numerous factors, such as the small dimensions of the samples resulting in a maximum of 2 tufts per sample, the aforementioned damage introduced to the composite and issues with the test itself. The test causes a great deal of compressive stress beneath the loading roller, increasing the risk of crack initiation within the matrix and making the generation of reproducible results difficult. The bending moment caused by the configuration of the test contributes to the deformation of the sample which introduces undesired stresses preventing the true value for shear strength being obtained. ${ }^{33}$

\section{CONCLUSION}

Depending on the material used the influence of the tufting yarns on the mechanical properties of the composite varies substantially. A positive correlation between the ultimate tensile strength of the fibres and the ultimate tensile strength of the composite has been observed. It is postulated that these tufting yarns enhanced load transfer within the composite, as per their improvement in UTS. The damage caused to the fibre component of the composite by the insertion of the polymer tufting yarns has been shown. Not only has it broken/ruptured some of these fibres it has also caused misalignment of the surrounding fibres resulting in resin-rich regions around the polymer stitches. It is expected that some of the variation in the mechanical results may be attributed to the varying fibre volume content. It is hypothesised that further work with the placing of tufting yarns in this study could have achieved a much more significant increase in the open-hole tensile strengths.

Diameter variations of the polymer yarns, and their ability to bend without fracture or kinking, were the only factors in this study which prevented some yarns from being able to be tufted, and so were excluded.

Following theoretical calculations on the Young's modulus of the materials showed that all of the yarns, aside from the PPSU, performed as expected. Due to the difficulty in tufting the PPSU yarn, with its breaking multiple times during the process, it is thought that its reinforcement properties were not that of its full potential of the material. 
The PSU, PES and PPSU tufting yarns were also found to be sites of porosity throughout the composite layers. The only yarn where this did not occur was the PEEK which had the lowest diameter and the smoothest surface topography.

None of the tufting yarns performed well in the short-beam shear strength testing, with the PES decreasing the short-beam shear strength by $17.3 \%$. This could be due to a number of factors such as; the small dimensions of the samples resulting in a maximum of 2 tufts per sample, damage introduction into the composite and issues with the test itself. The test causes a great deal of compressive stress beneath the loading roller. The bending moment caused by the test configuration may introduce undesired bending stresses preventing the true value for shear strength being obtained. However, the introduction of the tufting yarns decreased the variation in the short-beam shear strength when compared to that of the non-tufted alternative.

\section{Acknowledgements}

The author would like to thank Daniel Breen, Sam Wilson and Oran Walsh for their assistance with the project. This work was carried out under EPSRC grant number EP/L02697X/1 and was part funded by the Department for Employment and Learning (Northern Ireland Executive).

\section{References}

\footnotetext{
${ }^{1}$ Aktas A, Potluri P, Porat I, Group TC. Multi-needle stitched composites for improved damage tolerance. ICCM17. 2009;
}

${ }^{2}$ Beaumont PW., Soutis C, Hodzic A. Structural Integrity and Durability of Advanced Composites: Innovative Modelling Methods and Intelligent Design [Internet]. First. Beaumont PW., Soutis C, Hodzic A, editors. Cambridge: Woodhead Publishing; 2015. 872 p. Available from: https://books.google.co.uk/books?id=esmcBAAAQBAJ\&printsec=frontcover\&source $=\mathrm{g}$ bs_ge_summary_r\&cad $=0 \# \mathrm{v}=$ onepage $\& \mathrm{q} \& \mathrm{f}=$ false

${ }^{3}$ Jain LK, Dransfield K a., Mai Y-W. Effect of Reinforcing Tabs on the Mode I Delamination Toughness of Stitched CFRPs. J Compos Mater. 1998;32(10):2016-41. 
${ }^{7}$ Hartley JW, Kratz J, Ward C, Partridge IK. Effect of tufting density and loop length on the crushing behaviour of tufted sandwich specimens. Compos Part B Eng [Internet]. 2016;(December). Available from: https://doi.org/10.1016/j.compositesb.2016.12.037

${ }^{8}$ Treiber J. Performance of tufted carbon fibre / epoxy composites. Cranfield University; 2011.

${ }^{9}$ Najafloo B, Rezadoust AM, Latifi M. Effect of through-the-thickness areal density and yarn fineness on the mechanical performance of three-dimensional carbon-phenolic composites. J Reinf Plast Compos. 2016;35(20):1447-59

${ }^{10}$ Scott M, Dell'Anno G, Clegg H. Effect of Process Parameters on the Geometry of Composite Parts Reinforced by Through-the-Thickness Tufting. Appl Compos Mater. Applied Composite Materials; 2018;1-12.

${ }^{11}$ Dell'Anno G, Treiber JWG, Partridge IK. Manufacturing of composite parts reinforced through-thickness by tufting. Robot Comput Integr Manuf [Internet]. Elsevier; 2016;37:262-72. Available from: https://doi.org/10.1016/j.rcim.2015.04.004

${ }^{12}$ Beier U, Fischer F, Sandler JKW, Altstädt V, Weimer C, Buchs W. Mechanical performance of carbon fibre-reinforced composites based on stitched preforms. Compos 
Part A Appl Sci Manuf [Internet]. 2007;38(7):1655-63. Available from: https://doi.org/10.1016/j.compositesa.2007.02.007

${ }^{13}$ Markus Schneider CK. Carbon Fibre Sewing Yarn for Structural Reinforcement of Composites and Textile Applications. JEC Compos. 2006;24:63-5.

${ }^{14}$ Dooher T, McGarrigle C, Dixon D, McIlhagger A, Harkin-Jones E, Archer E. Novel thermoplastic yarn for the through-thickness reinforcement of fibre-reinforced polymer composites. J Thermoplast Compos Mater [Internet]. 2017;089270571774329. Available from: https://doi.org/10.1177/0892705717743290

${ }^{15}$ Harold G, Mount III E, Wagner J. Extrusion: The Definitive Processing Guide and Handbook [Internet]. Andrew W, editor. New York: William Andrew, Inc; 2004. 1-560 p.

${ }^{16}$ ASTM International. ASTM D3039/D3039M-14 Standard Test Method for Tensile Properties of Polymer Matrix Composite Materials. Am Stand Test Methods. 2014;

${ }^{17}$ ASTM International. ASTM D3217 / 3217M Standard Test Methods for Breaking Tenacity of Manufactured Textile Fibers in Loop or Knot Configuration. Am Stand Test Methods. 2015;7.

${ }^{18}$ Cytec. CYTEC CYCOM $® 890$ RTM Resin System Material Data Sheet. Tech Data Sheet - Aerosp Mater [Internet]. 2013;(August 2010):7. Available from: http://www.eaircraftsupply.com/MSDS/93251Cytec CYCOM 890 RTM tds.pdf

${ }^{19}$ Irving PE, Soutis C. Polymer Composites in the Aerospace Industry [Internet]. Irving PE, Soutis C, editors. Cambridge: Woodhead Publishing Limited; 2014. 536 p. Available from:

https://books.google.co.uk/books?id=IiR0AwAAQBAJ\&printsec $=$ frontcover\&source $=\mathrm{g}$ bs_ge_summary_r\&cad $=0 \# \mathrm{v}=$ onepage $\& q \& \mathrm{f}=$ false

${ }^{20}$ PT Curtis, CRAG Test Methods for the Measurement of the Engineering Properties of Fibre Reinforced Plastics, Royal Aerospace Establishment Technical Report 88012 , February 1988 
${ }^{23}$ Cytec. CYTEC CYCOM ${ }^{\circledR} 890$ RTM Resin System Material Data Sheet. Tech Data Sheet - Aerosp Mater [Internet]. 2013;(August 2010):7. Available from: http://www.eaircraftsupply.com/MSDS/93251Cytec CYCOM 890 RTM tds.pdf

${ }^{24}$ ASTM International. ASTM D3039/D3039M-14 Standard Test Method for Tensile Properties of Polymer Matrix Composite Materials. Am Stand Test Methods. 2014;

25 ASTM International. ASTM D5766/D5766M-11 Standard Test Method for Open-Hole Tensile Strength of Polymer Matrix Composite Laminates. Am Stand Test Methods. 2011;

${ }^{26}$ ASTM International. D2344 Standard Test Method for Short-Beam Strength of Polymer Matrix Composite Materials. Annu B ASTM Stand. 2006;i(Reapproved):1-8

${ }^{27}$ Dransfield K.A., Jain LK, Mai Y-W. On the effects of stitching in CFRPs-I. mode I delamination toughness. Compos Sci Technol. 1998;58(6):815-27. Available from: https://doi.org/10.1016/S02663538(97)00229-7

${ }^{28}$ Mouritz AP, Leong KH, Herszberg I. A review of the effect of stitching on the in-plane mechanical properties of fibre-reinforced polymer composites. Compos Part A Appl Sci Manuf. 1997;28(12):979-91.

${ }^{29}$ Herszberg I, Bannister MK. Tensile Properties of Thin Stitched Carbon/epoxy Composites. In: 5th Aeronautical Conference. Melbourne; 1993. p. 213-8.

${ }^{30}$ Koissin V, Kustermans J, Lomov S V., Verpoest I, Van Den Broucke B, Witzel V. Structurally stitched NCF preforms: Quasi-static response. Compos Sci Technol 
[Internet]. Elsevier Ltd; 2009;69(15-16):2701-10. Available from:

https://doi.org/10.1016/j.compscitech.2009.08.015

${ }^{31}$ Ilegbusi OJ, Yang J. Porosity nucleation in metal-matrix composites. Metall Mater Trans A Phys Metall Mater Sci. 2000;31(8):2069-74.

32 Zhao Y, Lin R, Tran T, Yang C. Confined wetting of water on CNT web patterned surfaces. Appl Phys Lett. 2017;111(16).

${ }^{33}$ Feraboli PJ, Kedward KT. In Search of the True Interlaminar Shear Strength. 19th, Jt Am Soc Compos Soc Test Mater Comm D30 [Internet]. 2004;(805). Available from: http://www.lambolab.org/wp-content/uploads/03research/pub/04delam/2004-ASCmd 1.pdf 